\title{
24. New perspectives on the effects of natural gas extraction on groundwater quality
}

\author{
Zacariah L. Hildenbrand \\ The University of Texas at Arlington, United States \\ Brian E. Fontenot \\ The University of Texas at Arlington, United States \\ Doug D. Carlton Jr \\ The University of Texas at Arlington, United States \\ Kevin A. Schug \\ The University of Texas at Arlington, United States
}

Over the past decade natural gas has emerged as a versatile source of energy and has been described as a transition fuel. It has facilitated the shift from coal to renewable energy resources while helping reduce $\mathrm{CO}_{2}$ emissions and curtail the power sector's production of industrial chemicals (Vidic et al. 2013). Advancements in unconventional drilling techniques, such as hydraulic fracturing and shale acidisation, have made the extraction of natural gas from previously inaccessible deep shale formations both practical and profitable.

Hydraulic fracturing involves a pressurised injection of water, proppants and chemical additives to expand fissures or fractures in shale formation to release trapped gases. Acidisation uses large quantities of hydrochloric acid under low pressure to dissolve sediments and solids, which serves to increase the permeability of the shale formation.

Despite the effectiveness of these technologies in liberating sequestered natural gas, they are not without environmental risk and are a cause for concern in today's society. Anxieties over environmental stewardship, in conjunction with the prospect of using natural gas as a catalyst in achieving energy independence, have provided the impetus for a number of investigations designed to characterise the relationship between unconventional gas extraction and groundwater quality. 
At the forefront of the unconventional natural gas extraction discussion are concerns over the potential migration of methane gas, the leaching of harmful chemical compounds and the mishandling of produced waste. Each of these can have potentially negative effects on the surrounding groundwater. In areas where deep shale formations co-exist with shallow aquifers, methane - the main component of natural gas - can leach into private water wells from both natural and anthropogenic processes (Vidic et al. 2013).

Methane occurs naturally in two forms, biogenic methane and thermogenic methane. Biogenic methane is produced at shallow depths as a byproduct of bacterial metabolism. Thermogenic methane, the primary target of unconventional natural gas extraction, is formed by geological processes at depths exceeding 1000 metres as a function of high temperature and pressure transforming decomposing organic material into methane gas.

Isotopic (Osborn et al. 2011) and hydrocarbon ratio (Jackson, R.B. et al. 2013) analyses have been used to determine the source of methane found in private water wells in the Marcellus shale of Pennsylvania. The majority of methane detected was characteristic of deep, thermogenic methane that could only have been liberated through unconventional drilling activities. Methane was detected in approximately 80 per cent of the collected samples (Osborn et al. 2011) with concentrations reaching their highest levels in close proximity to natural gas wells. The root cause of methane contamination events could be attributed to the opening of fractures by unconventional drilling activities that allowed thermogenic methane to migrate into water wells from abandoned historical gas wells (Jackson, R.E. et al. 2013).

In the case of Pennsylvania, approximately 350,000 legacy oil and gas wells have been drilled and the exact locations of $\sim 100,000$ of these are unknown (Pennsylvania Department of Environmental Protection). Additionally, instances of methane and chemical contamination can result from gas-well casing failures, a phenomenon that occurs in approximately three per cent of new gas well operations (Vidic et al. 2013). Changes induced by hydraulic fracturing can also facilitate advective transport of fracturing fluid and flowback into groundwater aquifers depending on the hydraulic conductivity and the presence of waterfilled voids in the geological formation (Saiers and Barth 2012).

In addition to the aforementioned pathways where groundwater can be directly affected by unconventional drilling activity, our research team at The University of Texas at Arlington has examined the effects of unconventional natural gas extraction on groundwater quality and found evidence for indirect mechanisms that could potentially lead to groundwater contamination (Fontenot et al. 2013).

In a recent peer-reviewed study published in Environmental Science and Technology, our team sampled 100 private water wells to assess the potential effects of natural gas extraction on water quality in the Barnett Shale formation 
of north Texas (see Figure 1). Our analyses revealed levels of heavy metals above the US Environmental Protection Agency's Maximum Contaminant Limit (MCL) for drinking water in private water well samples collected near natural gas extraction sites. Most notably, 29 of the 91 samples collected within five kilometres of an active natural gas extraction site had arsenic concentrations above the MCL of ten parts per billion (ppb), with a maximum concentration of $161 \mathrm{ppb}$.

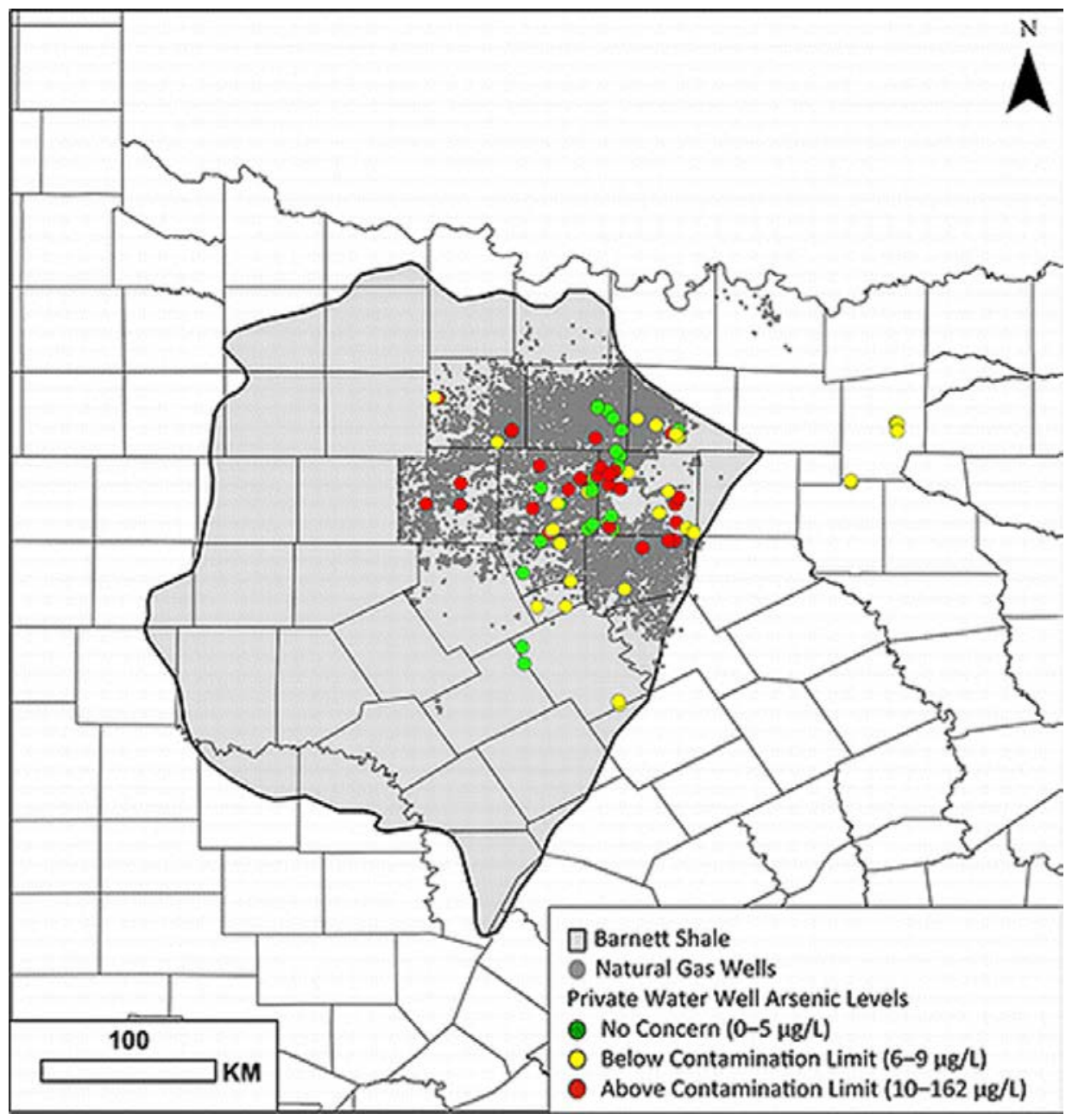

\section{Figure 1: Map of the Barnett Shale aquifer and the study area}

Source: Reprinted with permission from Fontenot et al. 2013. Copyright 2013 (American Chemical Society).

The maximum concentration discovered in one well was nearly 18 times greater than both the maximum concentration sampled from private water well samples located more than 14 kilometres from any active gas wells and the maximum 
concentration sampled from historical data collected in the Barnett Shale prior to the expansion of unconventional extraction activities (http://www.twdb.state. tx.us/groundwater/data/). We also found selenium and strontium at elevated concentrations, with selenium detected exclusively within two kilometres of natural gas wells.

One plausible explanation for the observed results involves large withdrawals of groundwater used in hydraulic fracturing operations that could cause localised declines in the water table. Such decreases can be associated with higher arsenic content in waters drawn from shallow water wells (Reedy et al. 2007). Another scenario to explain elevated heavy metals could be the mechanical vibrations produced from unconventional drilling activity. In this scenario, vibrations from nearby intense drilling activity could mechanically disturb a poorly maintained private water well that has accumulated rust, sulfate and/or carbonate scale. Once the rust and scale in the water well are disturbed, arsenic, selenium and strontium that were previously bound in oxide complexes could be mechanically liberated and released into the well water (Fontenot et al. 2013).

Our understanding of the relationship between groundwater quality and unconventional natural gas extraction is evolving. Future studies should focus not only on direct mechanisms of contamination from unconventional drilling activities such as fluid and methane leaks, but also on indirect mechanisms that could potentially lead to groundwater contamination. Additionally, a greater emphasis needs to be placed on the collection of baseline measurements prior to unconventional drilling activities.

In highly productive regions like the Bakken shale formation of North Dakota, or the Barnett, Eagle Ford and Wolfcamp shales of Texas, drilling operators are not required to perform baseline testing, making the characterisation of potential industrial contamination events extremely difficult. California is one of several states that have proposed legislation where groundwater monitoring efforts would be required before and after any well stimulation, as well as proposals for procedures to safely recycle or dispose of produced and flowback wastewaters. Whether these proposed laws are established and become more widely accepted remains to be determined. Regardless, the collection of baseline measurements prior to any natural gas extraction is the most direct way to quantify the environmental effects of unconventional drilling activity, and will greatly enhance our understanding of the relationship between shale gas extraction and groundwater quality.

Dr Zacariah L. Hildenbrand received his BSc and $\mathrm{PhD}$ from the University of Texas at El Paso. He is currently a faculty Research Associate at The University of Texas at Arlington where he is a lead scientist and project manager for several research studies analysing groundwater quality in the Barnett and Cline shale formations. 
Dr Brian E. Fontenot graduated with a $\mathrm{PhD}$ in quantitative biology from The University of Texas at Arlington in 2009. His past research focused on genetics, ecology and hybridisation in animals, but he currently uses his background in statistical analysis and experimental design as part of a team of researchers at The University of Texas at Arlington studying water quality in areas of natural gas extraction in the Barnett Shale formation.

Doug D. Carlton Jr is a PhD student in the Department of Chemistry and Biochemistry at The Univesity of Texas at Arlington.

Kevin A Schug is Associate Professor and Shimadzu Distinguished Professor of Analytical Chemistry in the Department of Chemistry and Biochemistry at the University of Texas at Arlington. He received his BSc degree in chemistry in 1998 from the College of William and Mary and his PhD degree in chemistry from Virginia Tech in 2002 under the supervision of Prof. Harold M. McNair.

\section{References}

Fontenot, B.E., Hunt, L.R., Hildenbrand, Z.L., Carlton Jr., D.D., Oka, H., Walton, J.L., Hopkins, D., Osorio, A., Bjorndal, B., Hu, Q.H. and Schug, K.A., 2013. An evaluation of water quality in private drinking water wells near natural gas extraction sites in the Barnett shale formation', Environmental Science \& Technology 47(17):10032-40.

Jackson, R.B., Vengosh, A., Darrah, T.H., Warner, N.R., Down, A., Poreda, R.J., Osborn, S.G., Zhao, K. and Karr, J.D., 2013. 'Increased stray gas abundance in a subset of drinking water wells near Marcellus shale gas extraction', Proceedings of the National Academy of Sciences of the United States of America 110:11250-5.

Jackson, R.E., Gorody, A.W., Mayer, B., Roy, J.W., Ryan, M.C. and van Stempvoort, D.R., 2013. 'Groundwater protection and unconventional gas extraction: the critical need for field-based hydrogeological research', Ground Water 51(4):488-510.

Osborn, S.G., Vengosh, A., Warner, N.R. and Jackson, R.B., 2011. 'Methane contamination of drinking water accompanying gas-well drilling and hydraulic fracturing', Proceedings of the National Academy of Sciences of the United States of America 108(37):8172-6.

Reedy, R.C., Scanlon, B.R., Nicot, J.P. and Tachovsky, J.A., 2007. 'Unsaturated zone arsenic distribution and implications for groundwater contamination', Environmental Science \& Technology 41(20): 6914-9. 
Global Water: Issues and Insights

Saiers, J.E. and Barth, E., 2012. 'Potential contaminant pathways from hydraulically fractured shale aquifers', Ground Water 50(6):826-8.

Vidic, R.D., Brantley, S.L., Vandenbossche, J.M., Yoxtheimer, D. and Abad, J.D., 2013. 'Impact of shale gas development on regional water quality', Science 340(6134):1235009. 
This text taken from Global Water: Issues and Insights by R. Quentin Grafton, Paul Wyrwoll, Chris White and David Allendes, published May 2014 by ANU Press, The Australian National University, Canberra, Australia. 